\title{
Las huellas del camino. Culto y devoción a Nuestra Señora del Rocío en tierras americanas, cultura inmaterial de Andalucía
}

\author{
Guadalupe Romero-Sánchez \\ Universidad de Granada, España \\ Adailson José Rui \\ Universidade Federal de Alfenas, Brasil
}

Nuestra SEÑora del Rocío, ReINA de las Marismas

En el año 2017 se publicó la obra Religiosidad andaluza en América. Repertorios iconográficos coordinada científicamente por los profesores Francisco Montes González y Rafael López Guzmán y en la que participamos 11 investigadores, integrantes del grupo de investigación «Andalucía-América: patrimonio cultural y relaciones artísticas» (HUM806). ${ }^{1}$ Con ella se puso de relieve la importancia de los caminos devocionales en la difusión de determinados cultos de origen andaluz por el mundo, el resultado fue el análisis de más de 40 iconografías que se concretaron en estudios específicos de su expansión por el continente americano, con incidencias desiguales. Así, de las advocaciones con soporte histórico se analizó la figura de San Juan de Dios (Granada) o la de San Fernando (Sevilla) como las más destacadas, además de otras muchas devociones; y de los cultos marianos, profundamente arraigados en Andalucía, la Divina Pastora (Sevilla), la Virgen de la Esperanza Macarena (Sevilla) y la Virgen del Rocío (Huelva). Es sobre esta última advocación sobre la que ahora

\footnotetext{
${ }^{1}$ López Guzmán, Montes GonzÁLez 2017.
} 
centramos la mirada de manera particular, pues, sus características hacen que su lectura sea diferente a la del resto de iconografías andaluzas presentes en América, pues su culto está ligado mayoritariamente a los grupos de emigrantes andaluces asentados en diferentes países y su extensión lejos de producirse en los siglos de la época moderna, es mucho más reciente y actual.

En origen, y como muchas otras imágenes marianas, la Virgen del Rocío, también conocida como "La Blanca Paloma" o "Reina de las Marismas" cuenta con una leyenda aparicionista según la cual la talla fue encontrada por un cazador en el paraje donde hoy se encuentra su ermita. Tal revelación motivó el deseo de muchas personas de ir al lugar para venerar a la Madre de Cristo en la forma inicial de la Virgen de los Remedios, poco después conocida como Virgen de las Rocinas según el nombre del lugar². Según las descripciones conservadas en origen podría haber tenido una imagen muy parecida a la Virgen de la Hiniesta. En la actualidad la Virgen está representada en Majestad, sosteniendo al Niño Jesús con ambas manos en el centro de la composición. Este cambio iconográfico fue el resultado de un proceso de transformación que se inició en el siglo XVI y XVII que mutilaría la talla para poder ser vestida como Reina con ricos tejidos ${ }^{3}$ [figs. 1 y 2 ].

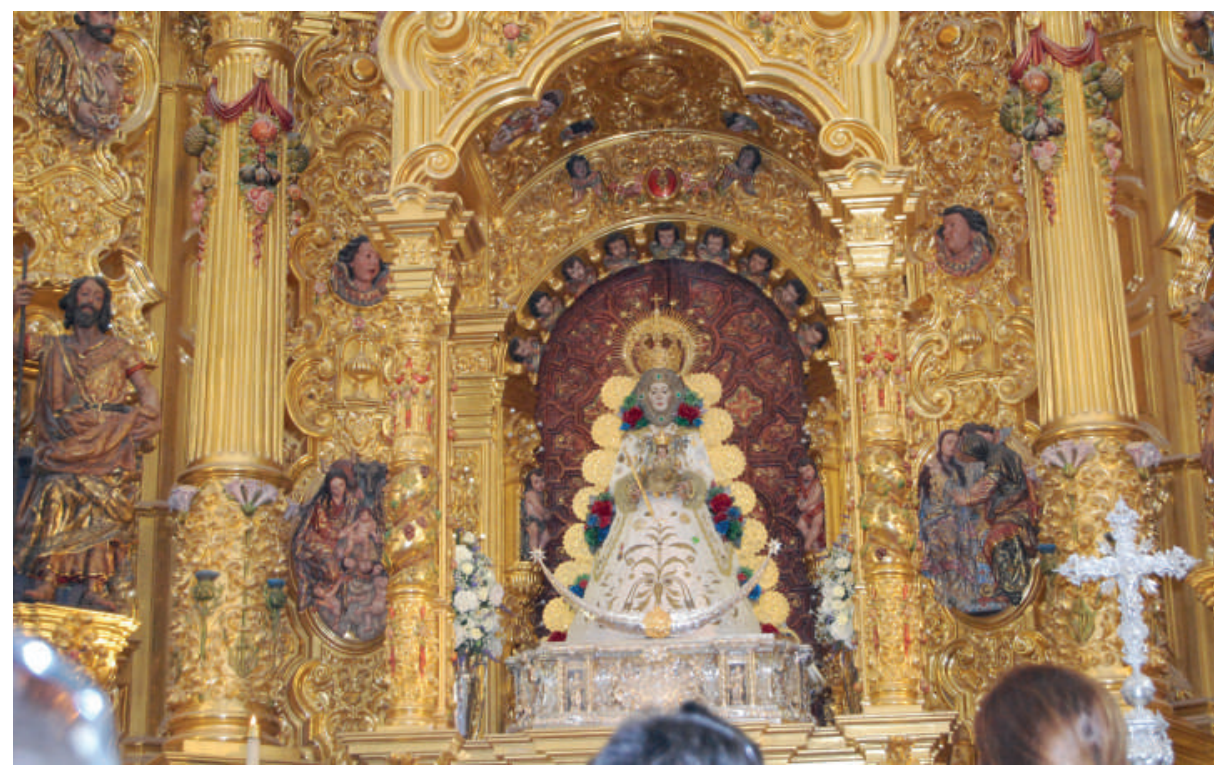

Fig. 1. Virgen de la Hiniesta. Talla de Antonio Castillo Lastrucci, 1945. Iglesia Parroquial de San Julián, reproducción de la original. Fuente: Francisco Montes González.

\footnotetext{
2 Romero-Sánchez y Rui 2020.

${ }^{3}$ Carrasco Terriza 2002, 1992.
} 


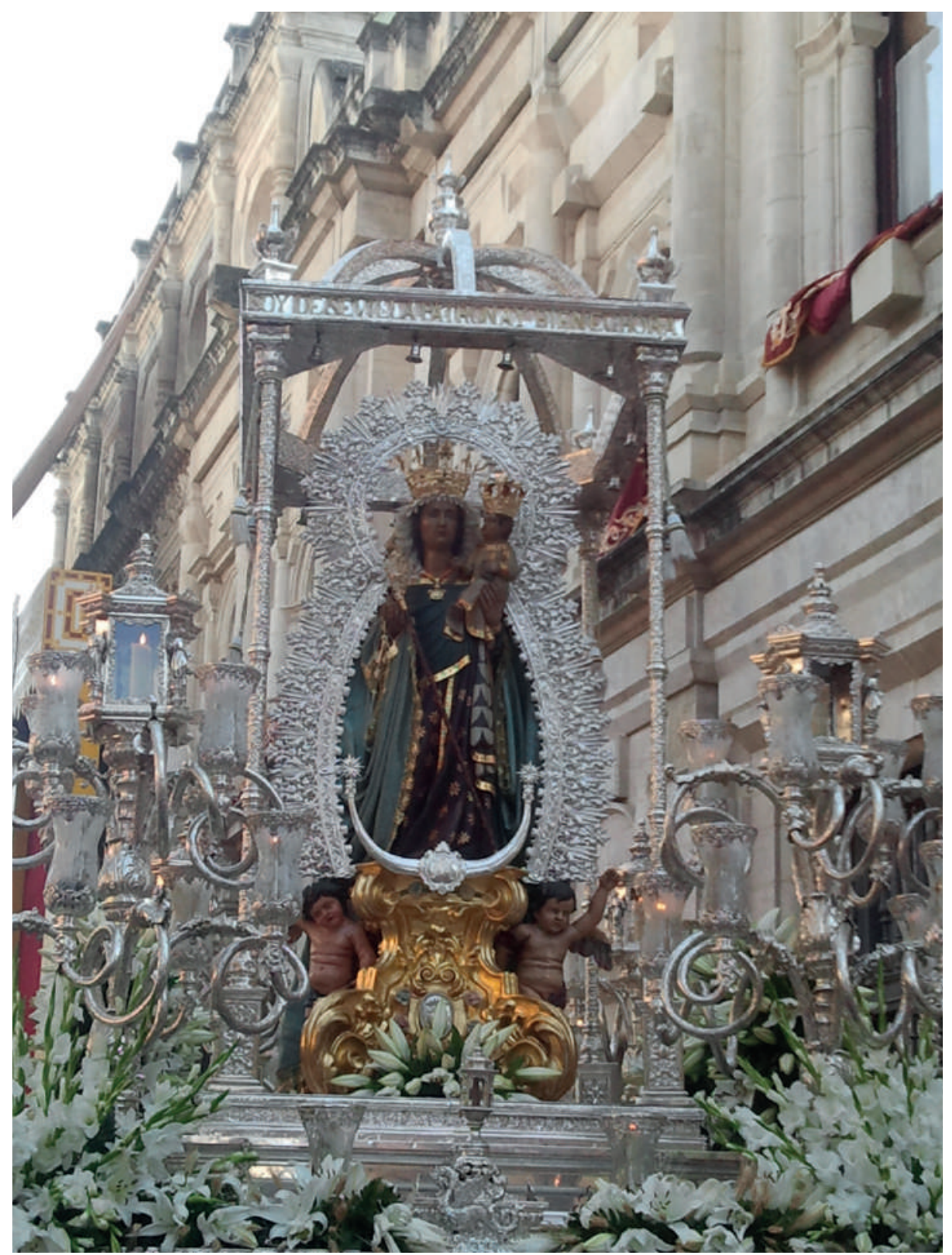

Fig. 2. Nuestra Señora del Rocío. Santuario de la Virgen del Rocío. Aldea del Rocío. Huelva. Fuente: María Lourdes Gutiérrez Carrillo. 
En este período de época moderna tuvo lugar también el auge de su culto, coincidiendo con una época de bonanza económica que se reflejó en el propio edificio de la ermita. Son muchas las donaciones que se reciben por parte de sus fieles, no obstante, por nuestra mirada internacional queremos resaltar la realizada por Baltasar Tercero desde Lima que resultó de especial importancia para la expansión de la devoción a la Virgen del Rocío. Este personaje se estableció en la Ciudad de los Reyes entre 1556 y 1594, año de su muerte, ejerciendo los oficios de cerrajero, armero, orfebre y relojero, así como comerciante o distribuidor de diferentes bienes, con los que consiguió hacer una considerable fortuna $^{4}$. Como puede ser habitual en el caso americano, estos personajes, enriquecidos en las Indias, deseosos de un mayor honor por su apellido y temerosos de Dios, destinaban una parte de sus bienes para la adquisición de objetos suntuosos que sirvieran de ornato para las imágenes de los templos de los que se era devoto, ordenando además la creación de obras piadosas, así como capellanías para la mayor gloria de sus almas. En otras ocasiones sus legados fueron puramente monetarios y sus inversiones se destinaron a diferentes caminos, como la mejora de los templos tanto en lo constructivo como en lo material ${ }^{5}$.

La donación de Baltasar Tercero se realizó por vía testamentaria en Lima el 11 de febrero de $1587^{6}$. A través del documento notarial se conoce que era hijo de Cristóbal Tercero y Catalina Ruiz, nacido en Córdoba y casado con Catalina Guerra, y aunque no la reconoció en su testamento, tuvo una hija en España llamada Inés de Torres, a la que reconocería más tarde ${ }^{7}$. Su legado a la Virgen del Rocío y la fundación de la capellanía han sido estudiados en otra ocasión ${ }^{8}$, no obstante, concluimos que su renta permitió hacer mejoras significativas en la ermita y en su ornato, lo que posibilitó dignificar el espacio y dar a conocer su advocación.

En estos años empezaron a realizarse también los traslados de la Virgen de la aldea donde se localiza la ermita al pueblo de Almonte (Huelva), al que pertenece, la fecha más antigua documentada es la del 1607. A mediados del siglo XVII por el número creciente de peregrinaciones y el aumento significativo de fieles comienzan a reglarse las celebraciones de los devotos, determinándose que las conmemoraciones se realizarían una vez al año en la Pascua de Pentecostés, estableciéndose así la Romería. De su organización se encarga la Pontificia, Real e Ilustre Hermandad Matriz de Nuestra Señora del Rocío de Almonte, heredera de la "Cofradía de Nuestra Señora de las Rocinas" fundada

\footnotetext{
${ }^{4}$ Infante GaLÁn 1971.

5 Romero-SÁNChez 2019.

${ }^{6}$ Archivo General de Indias (AGI), Contratación, 251, N.1, R.10, 10r-10v.

7 Cruz de Fuentes 1908.

${ }^{8}$ Romero-SÁNCHEZ y Rui 2020.
} 
a mediados del siglo XVII ${ }^{9}$. Relacionado con la Romería es el llamado Camino, que es el que realiza cada Hermandad, filial o no y las asociaciones rocieras, desde su lugar de origen hasta el Santuario del Rocío, confluyendo todas en el mismo punto los días álgidos de la celebración. Es, sin duda, la acción más conocida internacionalmente por el número de fieles que se congregan y por las características del camino en sí, que por ser de sobra conocidos no nos paramos a analizar. A día de hoy el culto a la Virgen del Rocío está en pleno auge y es una de las celebraciones más reconocidas internacionalmente, estando presente en la totalidad de los continentes [fig. 3].

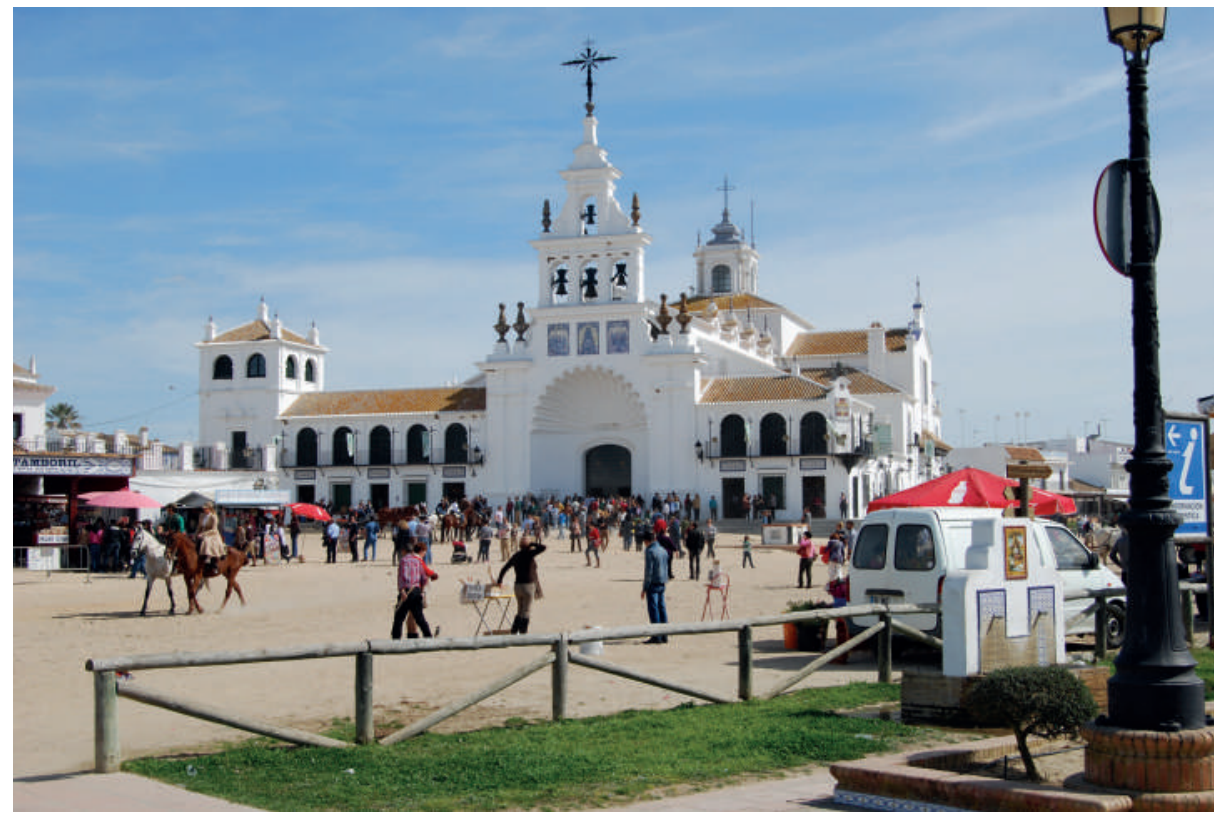

Fig. 3. Santuario de la Virgen del Rocío. Aldea del Rocío. Huelva. Fuente: María Lourdes Gutiérrez Carrillo.

Centrándonos en América, Carlos Garrido considera que "las raíces devocionales de la Virgen del Rocío están estrechamente relacionadas con las comunidades de emigrantes andaluces en los países iberoamericanos donde se encuentran estas imágenes" ${ }^{\prime 10}$, y efectivamente, en la mayoría de los casos documentados así ocurre, no obstante, también hay excepciones, enriqueciéndose los caminos devocionales.

${ }^{9}$ Pontificia, Real e Ilustre Hermandad Matriz de Nuestra Señora del Rocío de Almonte. Sitio web: https://hermandadmatrizrocio.org/historia/

${ }^{10}$ Garrido Castellano 2017: 283. 
Como advertimos anteriormente, la Hermandad Matriz de la Virgen del Rocío de Almonte se fundó a mediados del siglo XVII y unas décadas más tarde, en el cambio de centuria, se sitúan las primeras hermandades filiales de Villamanrique de la Condesa, Pilas, La Palma del Condado, Moguer y Sanlúcar de Barrameda. Con el tiempo se fueron sumando más hermandades, no obstante, va a ser en las últimas décadas del siglo XX y los primeros años del siglo XXI cuando se incrementen de manera notable llegando su número hoy a alcanzar las 125. Por otro lado, las Hermandades no filiales son 39 en España, contándose además 4 internacionales, localizadas en Mérida (Venezuela) llamadas Hermandad de Mérida y Rocieras de Corazón y otras dos en Argentina, en San Juan y en Venado Tuerto (Provincia de Santa Fe). Como asociaciones rocieras reconocidas se encuentran seis españolas y otras tantas exteriores, situadas en Ayacucho (Perú); Buenos Aires, Rosario y Santa Fe (Argentina); Masalla (La Paz, Bolivia) y San Juan (Puerto Rico). No obstante, los "caminos del Rocío" son mucho más extensos y su culto y devoción está cada vez más arraigados en América, como se podrá comprobar a través de esta investigación.

\section{ОвJETIVOS}

El principal objetivo de este estudio es aglutinar en un único documento las agrupaciones, centros culturales, hermandades y asociaciones más relevantes o activas que celebran culto al Rocío en tierras americanas, entendiendo como tal la totalidad del continente. Como podrá comprobarse a lo largo de estas páginas se trata de una devoción que cada año incrementa el número de sus fieles en todo el mundo y, particularmente, en América, donde las comunidades andaluzas están muy presentes, celebrando fiestas, romerías y procesiones que, en diversa escala, reproducen la fiesta del Rocío almonteña.

Estas asociaciones cuentan, por lo general, con una escultura de bulto redondo, generalmente una talla, que procede de algún taller andaluz, bien por medio de una donación o a través de una adquisición directa. Es cierto que la inmensa mayoría de agrupaciones rocieras existentes no están reconocidas por la Hermandad Matriz en ninguna de sus variantes, sin embargo, este hecho no lo consideramos relevante para su reconocimiento, pues con sus múltiples acciones contribuyen a la difusión y mantenimiento de la tradición rociera, que más allá de tener un carácter únicamente religioso, se trasciende este hecho para convertirse en un elemento cultural y social de enorme interés. Por tanto, otro de los objetivos es reconocer la labor cultural de estas asociaciones y agrupaciones y considerar sus actividades más allá de la fe, relacionándolo con 
los elementos patrimoniales intangibles, propios de la celebración y de la fiesta del Rocío.

\section{Metodología}

La estrategia metodológica que hemos seguido en esta investigación parte del desarrollo de los objetivos propuestos. En su análisis y tratamiento hemos seguido de manera sistemática un método descriptivo (en el estudio de cada una de las asociaciones, hermandades, centro culturales y agrupaciones localizadas), cualitativo (en la valoración global de los resultados obtenidos en relación a las características de estas asociaciones y en su funcionamiento), cuantitativo (en relación al número de asociaciones localizadas, entendidas como elementos sumativos) e inductivo (en la valoración general de los datos obtenidos, lo que nos ha permitido extraer una serie de conclusiones).

La búsqueda de los datos que se han incluido en este estudio se ha realizado a través de Internet. Hemos partido de la información aportada por la Hermandad Matriz de Almonte para localizar en primer lugar aquellas asociaciones y hermandades internacionales reconocidas por ellos, presentes en América. Por otro lado, hemos realizado un vaciado de la información contenida en dos de los portales rocieros más importantes y activos denominados "www.rocio. com" y "www.elrocio.net". A partir de los datos obtenidos hemos confeccionado una tabla en la que hemos añadido las referencias a las asociaciones americanas existentes, entendiendo estas en su acepción más extensa.

En paralelo, hemos revisado los listados de las entidades inscritas en el registro oficial de comunidades andaluzas de la Secretaría General de Acción Exterior de la Junta de Andalucía, dependiente de la Consejería de la Presidencia e Igualdad, de la que extrajimos los datos de 35 centros con sede en diferentes países americanos. Con estos centros contactamos de manera oficial bien mediante correo electrónico o a través de sus páginas de Facebook, pues muchas de estas entidades son muy activas en redes sociales informando de sus actividades. A ello se suman las publicaciones en diferentes diarios internacionales en relación a las acciones de estas asociaciones y al necesario análisis historiográfico de la producción científica editada en relación al culto a la Virgen del Rocío y su celebración tanto en Almonte como en los municipios y ciudades americanas sujetas a análisis.

Con los datos obtenidos del casi centenar de asociaciones localizadas en territorio americano presentamos una descripción de las que consideramos más relevantes bien por su antigüedad, bien por su singularidad o bien por su actividad. Su análisis lo realizamos por orden alfabético de países. 


\title{
LA Virgen del rocío en América
}

\begin{abstract}
Argentina
Por lo que respecta a Argentina son muchos los lugares donde el culto a la Virgen del Rocío está implantado. Ya mencionamos que dos agrupaciones cuentan con el reconocimiento por parte de la Matriz de Almonte como Hermandades no Filiales como son las localizadas en San Juan y en Venado Tuerto (Provincia de Santa $\mathrm{Fe}$ ), así como otras asociaciones rocieras también reconocidas, ubicadas en Buenos Aires, Rosario ${ }^{11}$ y Santa $\mathrm{Fe}^{12}$, que son bastante conocidas, no obstante, no son las únicas existentes.

La comunidad andaluza afincada en el conurbano bonaerense se agrupa en el Centro Cultural de Andalucía de Buenos Aires (CeCABA), que son los encargados de organizar desde hace algunos años una misa, procesión y romería en honor a la Virgen del Rocío. Esta celebración, que en 2019 cumplió su 17 edición, ha sido declarada de Interés Municipal por el Ayuntamiento de Tres de Febrero, en cuya demarcación se encuentra la localidad de Santos Lugares. Es en este municipio donde se desarrollan las actividades programadas bajo el auspicio de la Junta de Andalucía, teniendo como centro el altar de la Basílica de Nuestra Señora de Lourdes ${ }^{13}$.

En San Luis, el culto a la Virgen del Rocío comenzó en torno a 2002 con el apadrinamiento de un granadino de Pinos Puente, Antonio Fuentes Benítez ${ }^{14}$, emigrado en el año 1952. Según nos informa el propio Fuentes, en 1994 el grupo de andaluces que integraba el Club Andaluz formaron la Asociación de la Virgen del Rocío, pudiendo viajar algunos de sus miembros en varias ocasiones a Almonte para participar de las fiestas y celebraciones. No fue hasta 2001 cuando encargaron la escultura de la Virgen, que mide 1 metro y 20 centímetros sin corona para entronizarla en la provincia de San Luis. En 2003, estando la imagen preparada fue bendecida en la Parroquia de Fátima, iniciando después la procesión que culminaría en la Iglesia de la Sagrada Familia, donde se custodia ${ }^{15}$. Desde entonces, cada año, se celebra una procesión muy concurrida en la que participan grupos de caballistas y asociaciones de Gauchos que acompañan y custodian a la Virgen.

11 LÁzARo JódAr 2010.

12 Vellés 2013.

13 Centro Cultural Andalucía de Buenos Aires (Argentina). Sitio web: http://www.cecaba.org. ar/modules.php?name $=$ An_Rocio

${ }^{14}$ Barceló y Fuentes Benítez 2005.

15 Portal de Noticias: rocio.com $/$ movil/noticias/ver.php?id=44\&site=514\&busqueda=
\end{abstract}


En San Juan la imagen de la Virgen del Rocío, que es una talla de considerable altura, se localiza en el Santuario de la Inmaculada Concepción ${ }^{16}$. Esta agrupación es especialmente activa y sus actividades pueden seguirse activamente desde su página de Facebook [fig. 4].

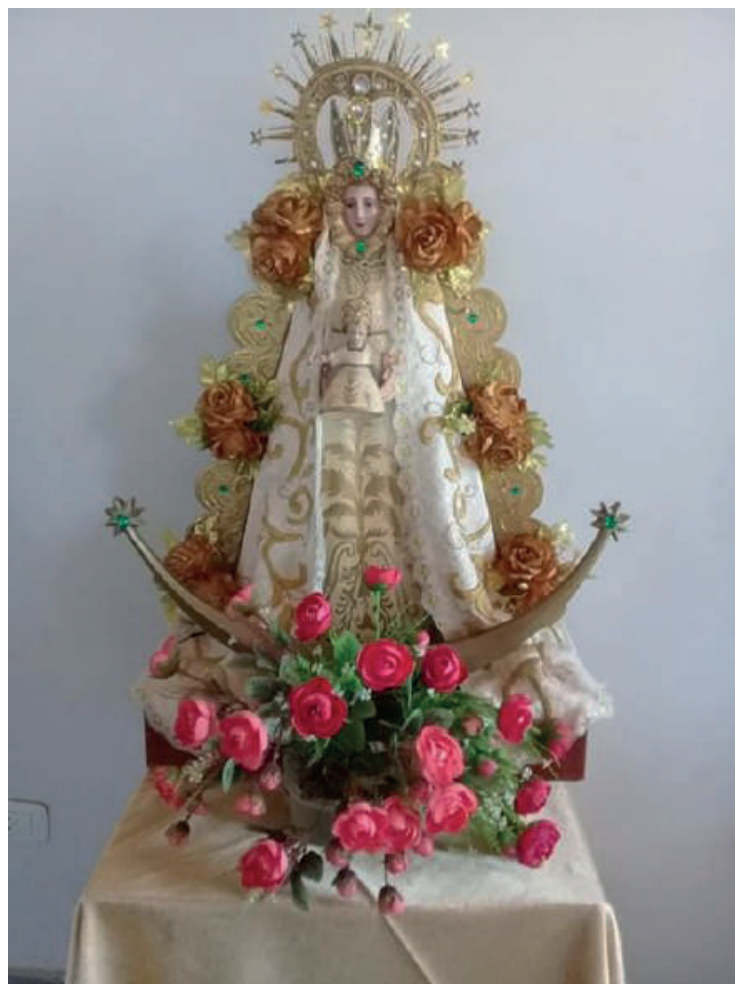

Fig. 4. Virgen del Rocío. San Juan (Argentina). Fuente: https://www.facebook.com/ 1571678789808884/photos/a.1580268265616603/2481555635487857/

En otros lugares de Argentina también encontramos esculturas de la Virgen del Rocío que indican que el culto a la Blanca Paloma está bastante expandido. Por ejemplo, en la cripta de la Basílica de Nuestra Señora de Luján, en la ciudad del mismo nombre, hay una escultura que forma parte del proyecto expositivo de la Basílica, ya que pretende recoger todas las invocaciones marianas presentes en el continente. Por otra parte, el Centro Andaluz de Rosario, entidad dependiente de la Federación de Asociaciones Argentinas, posee una escultura de un metro de altura de la misma advocación que lleva en procesión todos los

${ }^{16}$ Página de Facebook de la Hermandad de la Virgen del Rocío de San Juan (Argentina) https:/www.facebook.com/Hermandad-de-la-Virgen-del-Rocio-San-Juan-Argentina-15716787898 08884/ 
años, siguiendo las fiestas y actividades de su romería, aspectos que son similares a la tradición andaluza. Además, el Centro Andaluz de San Rafael cuenta con una monumental escultura contemporánea de la Virgen del Rocío a la entrada de su sede y, en su interior, una réplica de la imagen de Almonte, "con la que cada año los devotos procesan en una particular peregrinación tiene la parroquia de San Antonio de Padua de la localidad"17.

\section{BrasIL}

La experiencia del culto y las celebraciones en honor a la Virgen del Rocío andaluza están también presentes en Brasil, fundamentalmente a través de la acción de la comunidad española. No obstante, debemos advertir que en este país existe la advocación local a Nuestra Señora del Rocío de Paranaguá, patrona del estado de Paraná, que está muy extendida y que nada tiene que ver con la virgen almonteña. El hecho de que sean advocaciones homónimas ha generado a veces confusión, detectándose fusiones muy interesantes entre ambas celebraciones y cultos marianos, así, por citar un ejemplo, es significativo que

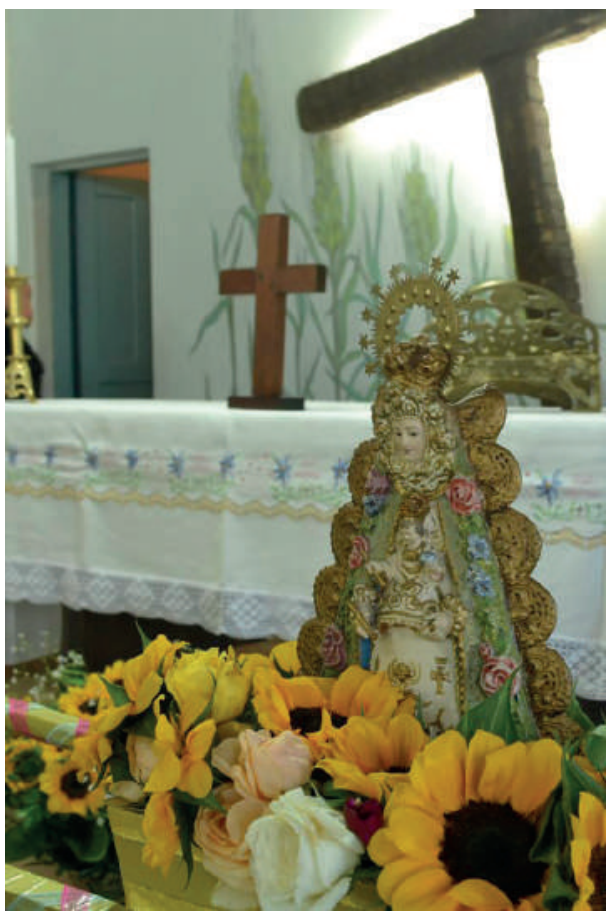
se celebre una misa en homenaje a la virgen de Paranaguá, en su día, 15 de noviembre, en una iglesia de Petrópolis, estado de Río de Janeiro, dedicada a Virgen del Rocío de Almonte. La misa es en honor a la Virgen del Rocío "brasileña", sin embargo, la imagen que preside el altar es una réplica de Nuestra Señora del Rocío de Almonte ${ }^{18}$ [fig. 5].

Fig. 5. Virgen del Rocío. Copia llevada desde España. Petrópolis. Paróquia São Judas Tadeu. Fuente: Diócesis Petrópolis (Brasil).

17 Garrido Castellano, C. 2017: 284-287.

18 Para más información sobre la Virgen del Rocío de Paranaguá ver: RoMERO-SÁNCHEZ y RUI, 2020. 
Ahora bien, como ocurre en otros países del continente, el culto a la Blanca Paloma en Brasil está relacionado también con el establecimiento de inmigrantes andaluces y con la creación de asociaciones culturales o casas regionales. En este sentido destacamos la actividad de las comunidades afincadas en Curitiba, capital del Paraná, y en Belo Horizonte, capital de Minas Gerais. En la primera de ellas, se encuentra el Centro Español de Paraná, cuya misión es "Mantener vivas las tradiciones de España a través de los emigrantes, sus descendientes y simpatizantes", entre estas tradiciones ocupan un lugar destacado las fiestas del Rocío que se llevan a cabo en marzo y abril, donde se realiza una procesión con una imagen de bulto de la Virgen de las Marismas, y donde hay representaciones flamencas y degustación de comidas típicas ${ }^{19}$. En el segundo de los casos la organización de la fiesta, que se celebra desde 1992 en julio, corre a cargo del Centro de Cultura Flamenca que tiene como misión mantener viva la cultura de origen entre los españoles afincados en Brasil y sus descendientes ${ }^{20}$.

En el estado de Río de Janeiro, en Quiçamã, diócesis de Nova Friburgo, el 7 de diciembre de 1995 se erigía canónicamente la Hermandad de Nuestra Señora del Rocío. Impulsada de la mano del misionero franciscano Carlos Guillena Rodriguez, natural del pueblo de los Molares (Sevilla) y padre de Quiçamã desde 1994 hasta 2011 cuando falleción ${ }^{1}$. Según relata uno de sus fieles, esta agrupación dedicó gran parte de los recursos a construir un hogar para los ancianos desamparados, cuya capilla parece ser que reproduce a escala reducida la fachada del santuario del Rocío. Cada 15 de agosto, día de la Asunción de la Virgen, celebran una romería en la que participan caballistas de la zona y donde se celebra una misa rociera acompañada del coro de la Casa de España de Río de Janeiro. La talla de la Virgen de Nuestra Señora del Rocío que sale en procesión con motivo de las fiestas fue llevada hasta esta región brasileña por el obispo de Huelva, quien viajó acompañado de varios sacerdotes diocesanos ${ }^{22}$.

\section{CHILE}

Existen varias asociaciones de andaluces en Chile que celebran el Rocío. Entre ellas destacamos el Centro Cultural Andaluz, presidido en la actualidad por Edgardo Aragú Pérez. Cada año desde este centro se celebra una misa rociera

${ }^{19}$ Centro Espanhol do Paraná. Sitio web: https://www.centroespanhol.com.br/eventos.

${ }^{20}$ Referencia: http://portalbelohorizonte.com.br/eventos/festa/gastronomia/24a-festa-espanhola-de-belo-horizonte-romeria-da-virgem-del-rocio

21 Alcántara Castillo 2011.

${ }^{22}$ Referencia: https://www.rocio.com/cgi-bin/yabb/YaBB.cgi?board=informacion;action=print; num=1279340935. Ver también: La Hermandad del Rocío de Brasil. Escrito por Periódico Rociero / Juan M. Curado. Portugal, domingo, 25 de abril de 2010. 
y una procesión que culmina en la Capilla de Nuestra Señora de Valvanera ${ }^{23}$ y durante la cual es llevada en andas, estando acompañada de numerosos fieles ${ }^{24}$. La talla de la Virgen, de pequeñas dimensiones, fue traída hace algunos años desde Andalucía.

\section{Estados Unidos}

En California existe desde el año 1992 la Hermandad de las Américas de Nuestra Señora del Rocio (Brotherhood of The Americas of Our Lady of Rocio), promovida por la Peña Andaluza bajo la dirección de Charo Monge y el resto de sus miembros, que celebra una reunión rociera una vez al año en el área de San Diego.

La Hermandad cuenta con una escultura de la Virgen del Rocío encargada al escultor nicaragüense Carlos Hernández en 2003, siendo un regalo de Nubia Balladares de Suárez a su hijo Roger Xavier. Mide 63,5 centímetros y su corona es de Lima, curiosamente la imagen tiene dos trajes, de reina y de pastora, al igual que la imagen de Almonte. Aunque la talla se conserva en la residencia privada de los Balladares hace frecuentes visitas a los templos de la zona, siendo "bendecida el miércoles de ceniza de 2004 por el cardenal Róger Mahoney en la catedral de Nuestra Señora de Los Ángeles, en Los Ángeles (California)" "25, "y el 31 de mayo de 2005, fue coronada por monseñor J.T. Murphy en la iglesia de San Víctor en la ciudad de West Hollywood"26.

Un aspecto reseñable de esta Hermandad es la celebración cada año de una romería en honor a la Virgen del Rocío, intentando recrear en tierras californianas parte de la fiesta andaluza y que tuvo su origen probablemente en el año 2006. Con motivo de esta celebración anualmente diseñan un cartel en el que convocan no solo a los andaluces establecidos en el territorio sino también a las comunidades hispanas, como la de la parroquia de San Patricio, a participar en una procesión que tiene probablemente el recorrido más largo en suelo americano, llegando a alcanzar en 2009 los 235 kilómetros de camino ${ }^{27}$. En

${ }^{23}$ Referencia: https://www.espanaexterior.com/noticias/dia-de-la-virgen-del-rocio-en-el-centro -cultural-andaluz-de-chile-8/

${ }^{24}$ En el siguiente enlace puede visualizarse un vídeo recopilatorio de las diferentes procesiones organizadas por el Centro. Esta composición fue realizada en 2020 al no poder celebrar ese año las fiestas a causa del COVID-19: https://www.youtube.com/watch?v=a2Rc6WTryQ0\&feature=youtu.be.

${ }^{25}$ Huelva, buenas noticias. Periódico, 22 mayo 2015. Consulta: 22/03/2019. Referencia digital: https://huelvabuenasnoticias.com/2015/05/22/el-rocio-usa-la-celebracion-de-la-romeria-almon tena-en-california/

${ }^{26}$ Referencia: http://www.elrocio.net/index.html.

27 En la página web de la Hermandad se muestran los carteles anunciantes de la Romería desde el año 2009, estos carteles son especialmente interesantes e invitamos a su visualización (http://www.elrocio.net/events.html). 
el recorrido se portan los simpecados de la Hermandad, yendo vestidos con los trajes populares de Andalucía, celebrándose una misa a la llegada al templo en honor a la Blanca Paloma y cantando posteriormente la Salve [fig. 6].

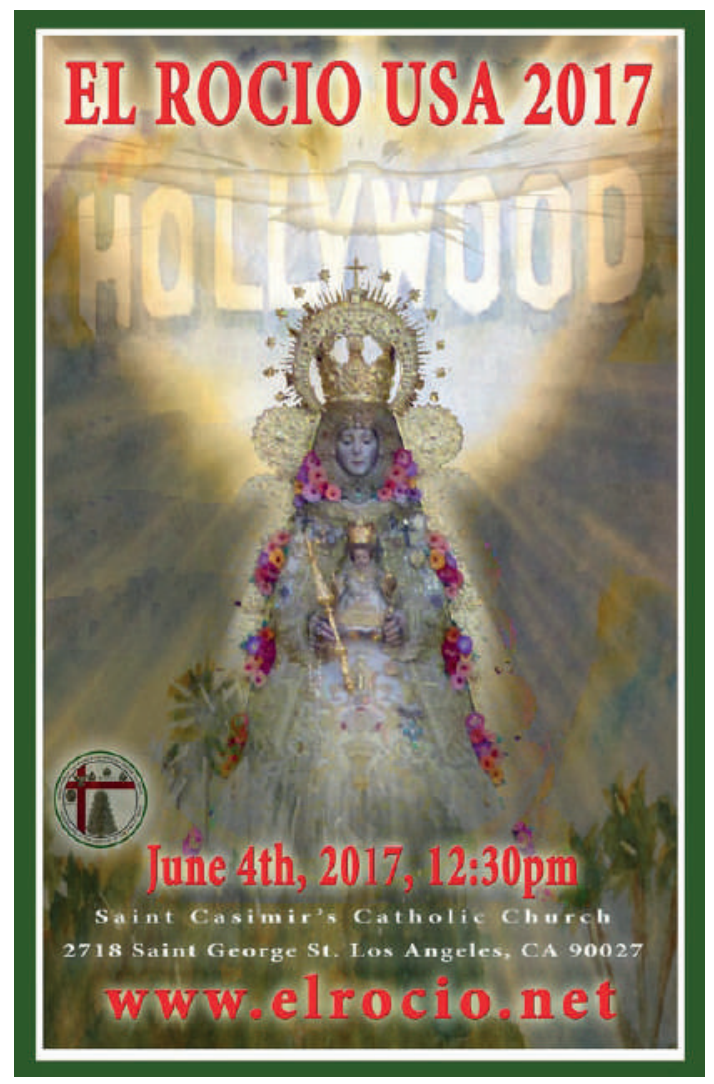

Fig. 6. Cartel de la romería a la Virgen del Rocío en California. (EE.UU). Hermandad de las Américas de Nuestra Señora del Rocío. Fuente: www.elrocio.net.

\section{MÉXICO}

En la ciudad de Querétaro se localiza la Colonia del Rocío, una de las más extensas de la urbe con una población estimada de 6.400 habitantes. En este barrio se alza un templo dedicado a Nuestra Señora del Rocío de Almonte que cuenta con una historia muy interesante y que, por su singularidad, queremos destacar particularmente. Fue hace 29 años que se inició el proyecto edilicio realizándose entonces una encuesta en el barrio para decidir la advocación de la futura iglesia. Durante el proceso hubo una propuesta de dedicar el templo a la 
Blanca Paloma por denominarse la colonia así, siendo aceptada esta petición por la comunidad.

El terreno donde se erige el templo era una propiedad baldía que fue donada generosamente por sus propietarios, de los que desconocemos el nombre. La obra se inició en noviembre de 1991, estando dirigida por el arquitecto Germán Navarrete, contando con la ayuda material de los alumnos del TEC de Monterrey y el apoyo económico mayoritario de Ricardo Vega, vecino de la zona, aunque también con las aportaciones significativas de otros miembros de la comunidad a través de diferentes colectas. Desde el inicio de la construcción y a pesar de las obras el templo tuvo culto y se celebraba la misa ordinariamente, siendo el obispo Mario de Gasperín y Gasperín quien presidiera las primeras celebraciones sacramentales y quien consagrara el templo.

Con capacidad para 250 personas, este edificio religioso, que se concluyó definitivamente en 2010, perteneció originalmente a la parroquia de Corpus Christi, ubicada en la Colonia Obrera, no obstante, a partir de 2006 pasó a depender de la Parroquia de la Divina Providencia en la Colonia Los Sauces.

Iniciado el proyecto de construcción de la capilla, fue también Ricardo Vega, junto a otros colonos, quien propuso que de dedicarse el edificio religioso a la Virgen de las Marismas debían conseguir una talla que fuera copia fiel de la original almonteña para presidir su altar mayor. No obstante, la primera imagen que llegó fue una fotografía de la Reina de las Marismas en el año 1992 de la mano de su yerno, Mariano Garfias, encargándose en 2003 la escultura de bulto que se venera hoy, probablemente en un taller andaluz. La talla llegó a tierras mexicanas la primera semana de junio del año 2004, instalándose entonces en la Parroquia del Corpus Christi, para desde allí, en domingo próximo caminar en procesión hasta la Capilla levantada en su honor, donde en la actualidad se localiza ${ }^{28}$.

Desde que llegara la imagen de la Virgen a la Colonia del Rocío, cada año se celebra la Fiesta Patronal, primero en el mes de mayo, para hacerla coincidir con la Romería en España, y desde hace 5 años a finales de junio, por decisión del Padre Vicario de la Parroquia a la que pertenece. Durante las fiestas se reúnen para rezar el Rosario, concluyendo con la Novena. Todos los días que duran los festejos suelen haber actividades culturales, culminando la celebración con una procesión de la Virgen del Rocío por su colonia y por otras colindantes, estando acompañada de danzas autóctonas y banda de música, hasta la celebración a las 17 de la tarde de una misa solemne de la que participa toda la comunidad ${ }^{29}$ [figs. 7,8 y 9 ].

28 Guerrero Granados 2019.

29 Agradecemos a María Trinidad Guerrero Granados, miembro destacado de la comunidad rociera de Querétaro, quien amablemente nos ha proporcionado los datos relativos a este apartado. 
Fig. 7. Virgen del Rocío. Copia llevada desde España. Templo de Nuestra Señora del Rocío. Querétaro (México). Fuente: María Trinidad Guerrero Granados.

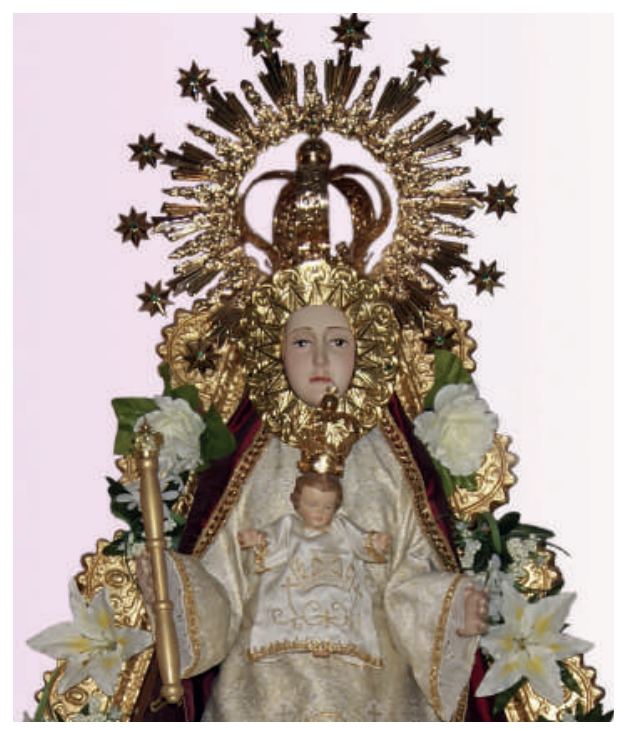

Fig. 8. Virgen del Rocío vestida de Pastora. Copia llevada desde España. Templo de Nuestra Señora del Rocío. Querétaro (México). Fuente: María Trinidad Guerrero Granados.

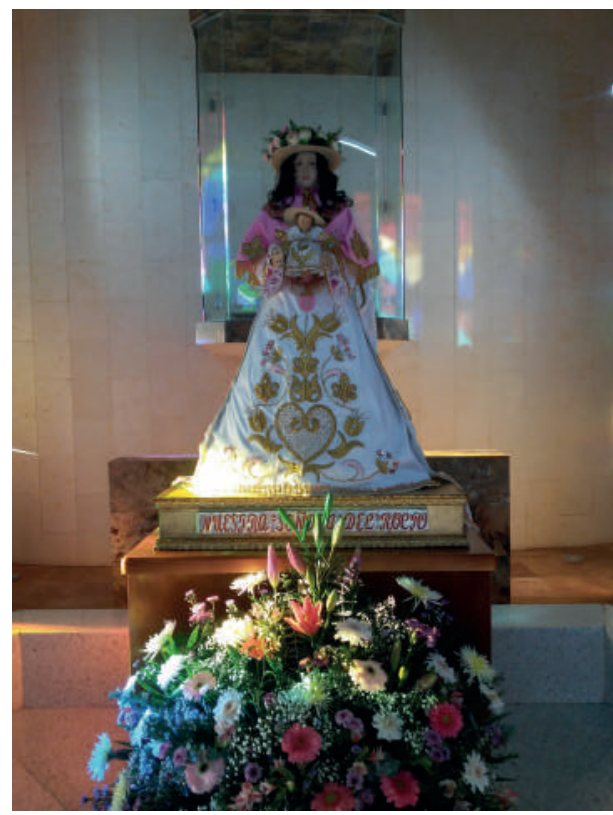




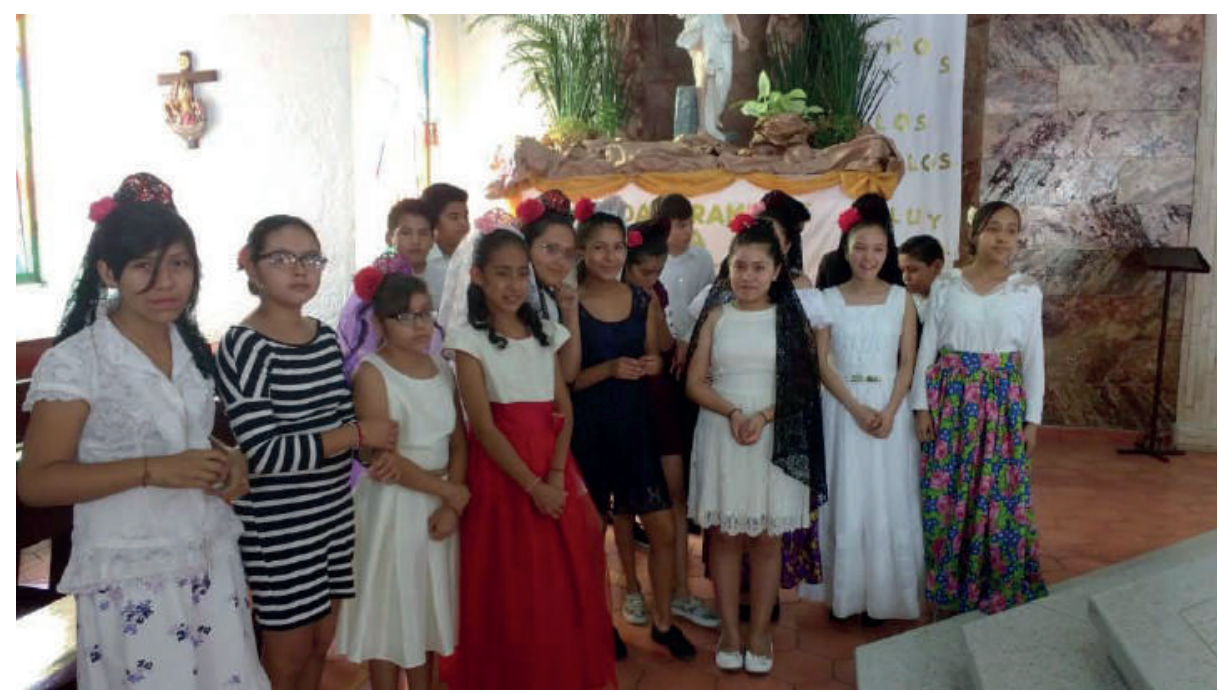

Fig. 9. Celebración rociera. Templo de Nuestra Señora del Rocío. Querétaro (México). Fuente: María Trinidad Guerrero Granados.

\section{Perú}

En Perú localizamos en Arequipa una escultura de $45 \mathrm{~cm}$, realizada por el escultor Teodor Pinilla y perteneciente a Jaime Herrera Valencia. Esta imagen forma parte de una colección privada y presumiblemente no participa en el culto popular. En otra región del país está la Asociación Hermandad Andino Amazónica Nuestra Señora del Rocío, su imagen escultórica tiene una mayor tradición. Según la propia Asociación, fue esculpida en Sevilla por el maestro Eduardo de Triana, quien realizó 5 esculturas que fueron bendecidas en la Iglesia del Pilar Polígamo de San Pablo en 1982. Adquirida posteriormente fue donada a esta Asociación, siendo la entrega coordinada por los consulados de Perú, en Sevilla, y de España, en Lima ${ }^{30}$ [fig. 10].

${ }^{30}$ Página de Facebook de la Asociación Hermandad Andino Amazónica Nuestra Señora Virgen del Rocío. Referencia: https://www.facebook.com/pages/category/Community-Service/Asociaci $\% \mathrm{C} 3 \% \mathrm{~B} 3 n-H e r m a n d a d-A n d i n o-A m a z \% C 3 \% B 3 n i c a-N$ tra-Sra-Virgen-del-Roc\%C3\%ADo- Per\%C3\%BA-1174409032685676/ 


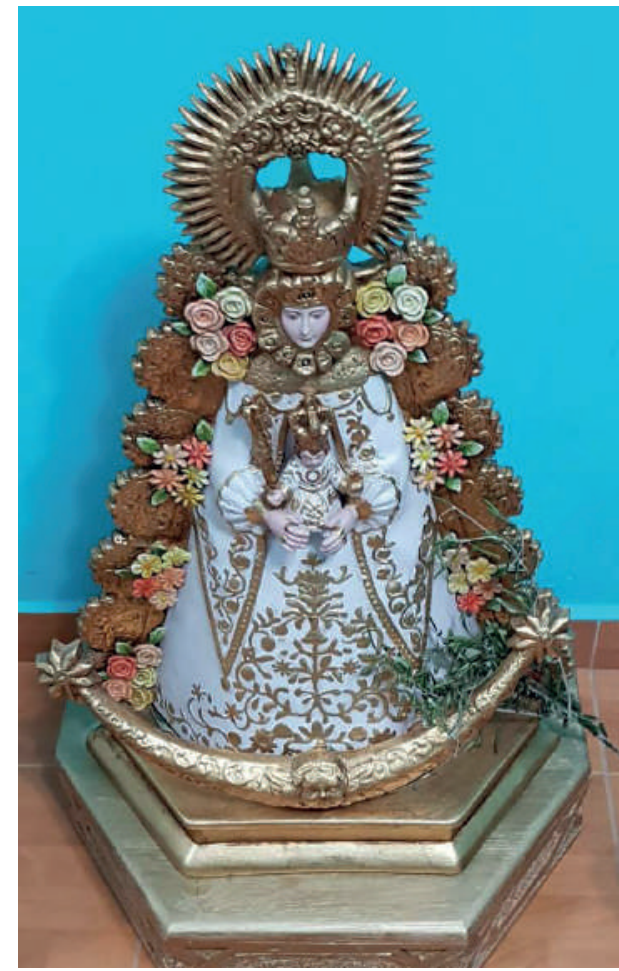

Fig. 10. Virgen del Rocío. Escultura de Eduardo de Triana. Asociación Hermandad Andino Amazónica Nuestra Señora del Rocío. Perú. Fuente: https://www.facebook.com/pages/category/Community-Service/Asociaci\%C3\%B3n-Hermandad-Andino-Amaz\%C3\%B3nica-Ntra-Sra-Virgen-del-Roc\%C3\%ADo-Per\%C3\%BA-1174409032685676/

Otro de los proyectos más interesantes y recientes llevados a cabo en Perú es la construcción de un hogar para niñas en exclusión social cuya fachada es una réplica exacta de la Ermita del Rocío almonteña. Las obras comenzaron en 2018, cuando se celebrara el Centenario de la Coronación Canónica de la Virgen del Rocío. Según su principal impulsor, el padre don Ignacio Doñoro, su erección es una forma de homenaje dentro de esta conmemoración de los 100 años a la Blanca Paloma de la que es especialmente devoto, afirmando sobre este centro de acogida: "El santuario español más reconocido traspasa las fronteras y en la selva, en medio de la nada, te encuentras una réplica exacta del Rocío"31.

El Hogar Nazaret, nombre del centro que hace las veces también de santuario mariano, se localiza en Bellavista, provincia de San Martín, en la selva

\footnotetext{
${ }^{31}$ Calderero de Aldecoa 2018.
} 


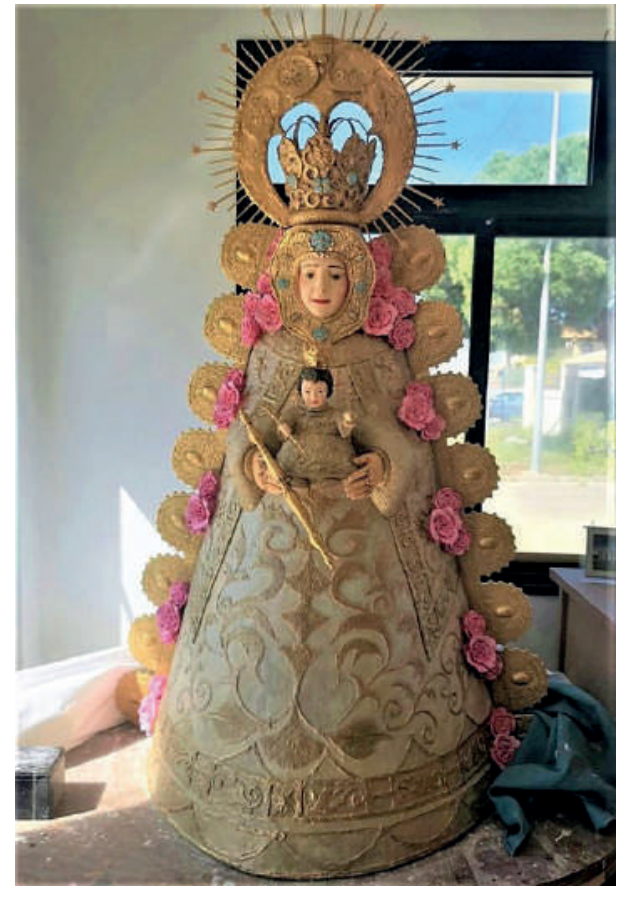

amazónica. En marzo de 2019 reciben la donación por parte del marqués Miguel Bejarano García y su familia de una escultura de la Virgen del Rocío, obra del artista cubano Jorge Estéfano Leyva, afincado en Almonte desde hace más de 15 años $^{32}$ [fig. 11].

Fig. 11. Nuestra Señora del Rocío. Jorge Estéfano Leyva. Bellavista - San Martín (Perú). Fuente: https://www. facebook.com/HogarNazaretOficial/ posts/2646297638791112

\section{Puerto Rico}

También en Puerto Rico encontramos en la Iglesia de San Germán de Auxerre una pequeña escultura policromada que se lleva en procesión todos los años, celebrando en esa ocasión una misa solemne cantada por un coro rociero ${ }^{33}$. También cuenta con una apretada agenda de actividades la Asociación Rociera del Centro Andaluz de San Juan en Puerto Rico, que además de celebrar la Romería del Rocío, también conmemora el Rocío Chico en septiembre, entre otros muchos eventos. Según informa Miguel Ángel Jiménez García: "La historia del nacimiento de esta asociación se remonta a mediados de los años 80, poco después de la incorporación oficial del Centro Andaluz de Puerto Rico al registro de la Junta de Andalucía. En una de las reuniones de este centro se decidió crear un grupo rociero. El presidente del centro, José Luis Garrido, aprovechó un viaje a Sevilla para comprar una imagen de la Virgen a la que más tarde se construyó un paso" 34 .

32 Página de Facebook del hogar de Nazaret. Referencia: https://www.facebook.com/HogarNazaretOficial/posts/2646297638791112

33 Garrido Castellano, C. 2017: 287.

34 JiMÉNEZ GARCía 2017. 


\section{VENEZUELA}

En Venezuela, la erección canónica de la Asociación de Nuestra Señora del Rocío de la Arquidiócesis de Mérida tuvo lugar el 26 de mayo de 2009, no obstante, su inscripción como agrupación rociera internacional en la Hermandad Matriz de Almonte tuvo lugar el 12 de febrero de 2013, siendo una de las escasas asociaciones que cuentan con este reconocimiento, como vimos anteriormen$t^{35}$. Esta asociación, hasta donde sabemos, tiene al menos una filial en Táchira, también en tierras venezolanas.

Por otro lado, la Hermandad de Rocieros de Corazón dispone de figura jurídica desde 1997 y el 5 de diciembre de 2014 recibieron la erección canónica por parte del Arzobispo de Mérida, teniendo su sede en la Parroquia Universitaria Jesús Maestro de Mérida ${ }^{36}$ [fig. 12].

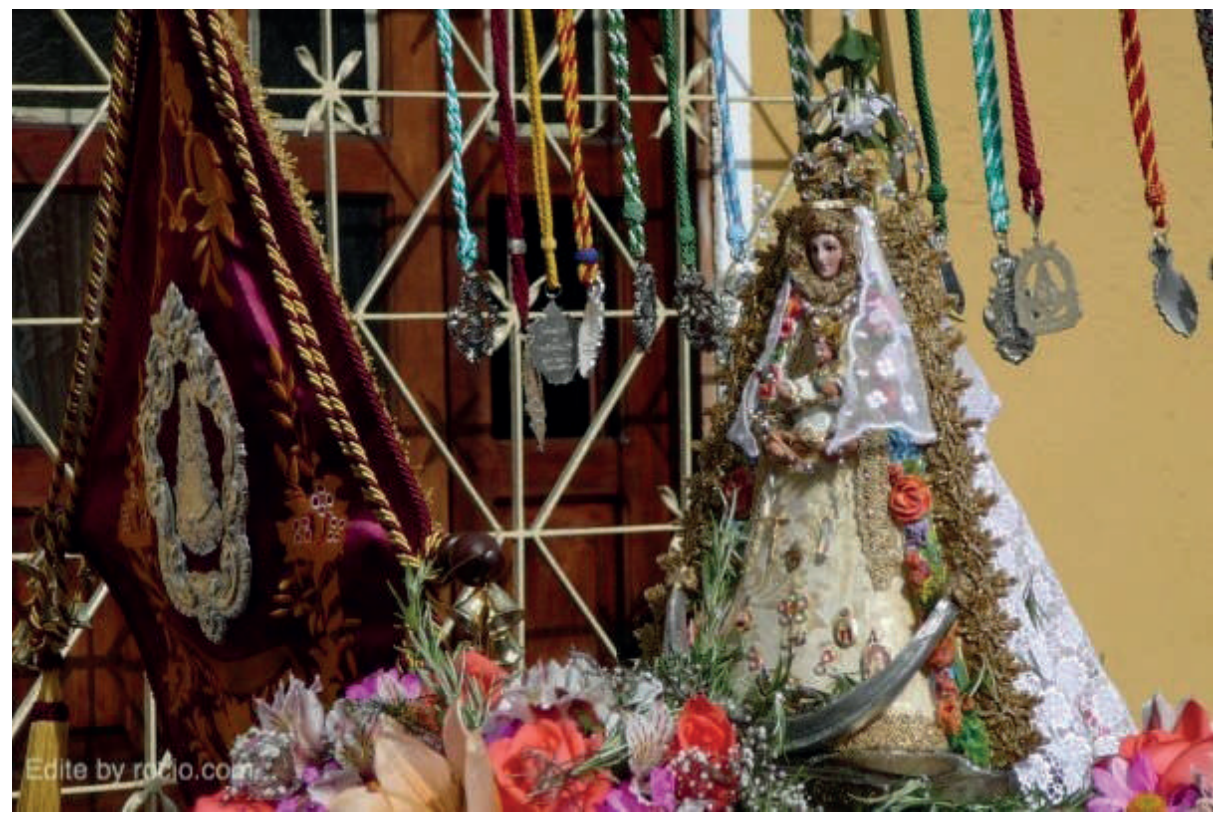

Fig. 12. Procesión de la Virgen del Rocío. Mérida (Venezuela). Fuente: Karelia Grisolia, www.rocio.com

${ }^{35}$ Referencia: https://www.rocio.com/agrupacion-ntra-sra-del-rocio-de-merida-venezuela/\#/

${ }^{36}$ Humilde, Fervorosa, Paciente y Caritativa Hermandad de Nuestra Señora del Rocío, Rocieros de Corazón. Sitio web: www.soyrociero.com 


\section{CONCLUSIONES}

La Virgen de Rocío está en América. Traída, generalmente, por los andaluces emigrados y afincados en diversos países del continente, hoy día es parte de la cultura religiosa de miles de creyentes, no sólo de origen andaluz sino también americanos. Las hermandades filiales o no filiales a la sede de Almonte y el resto de agrupaciones rocieras colaboran para la extensión de su culto existiendo una buena confraternización entre ellas. Las entidades mencionadas en este artículo no son las únicas existentes, son únicamente una selección atendiendo a los objetivos planteados con el fin de mostrar referencias amplias de la realidad del culto al Rocío en suelo americano.

Como hemos podido comprobar, la extensión de su devoción responde a aspectos de carácter religioso, pero también a características de índole cultural y social, como elementos integrantes de una tradición representativa del rico patrimonio inmaterial de Andalucía que trasciende las fronteras, convirtiéndose la celebración rociera en uno de los nexos de unión más reconocibles entre las comunidades de andaluces afincadas en el extranjero, responsables de la extensión de su fe. No obstante, esta no será la única vía de penetración pues a veces la implantación de su culto viene motivada por la devoción particular de algún personaje de cierto renombre destacando en este sentido, por ejemplo, la labor de Ignacio Doñoro en Perú; o también por la decisión de una comunidad que sin vínculos con Andalucía deciden dedicar su templo a la Blanca Paloma, caso de Querétaro, en México. Sin embargo, estos casos, aunque de enorme interés, no dejan de ser excepciones a la norma.

Todas las agrupaciones, asociaciones, centros culturales y hermandades a las que hemos atendido tienen como nexo común que son entidades que tienen cierta tradición y reconocimiento, y que además cuentan con una escultura de bulto redondo, generalmente una talla, de Nuestra Señora del Rocío, importada de una manera u otra desde Andalucía. La existencia de la imagen es fundamental, pues contribuye al desarrollo de las fiestas en honor a la Virgen, posibilitando realizar una pequeña romería y/o procesión que entronca con la festividad almonteña, por lo que este hecho no es baladí.

Igualmente, relevante consideramos la construcción, en zonas a veces muy inaccesibles, de edificios que imitan o representan la fachada de la ermita del Rocío. Son dos los ejemplos localizados, en Perú y en Brasil, ambas por iniciativa particular de sacerdotes españoles que desarrollan su labor en estos lugares y cuyas construcciones tienen fines sociales. Lamentablemente no hemos podido acceder a los proyectos constructivos de las obras ni contactar con los responsables de estos centros a fin de analizar estos espacios de una manera detallada, no obstante, en el caso de Perú se puede acceder a algunos enlaces 
web que permiten ver algunas de las imágenes de su proceso constructivo, certificándose su similitud a la Ermita del Rocío de la aldea almonteña.

Queda patente que el culto a la Virgen del Rocío está más vivo que nunca y crece de manera exponencial según pasa el tiempo. Cada año aumenta el número de asociaciones, agrupaciones y entidades rocieras en todo el mundo y particularmente en América, donde su culto se sigue extendiendo y arraigando en lugares muy diversos, fundamentalmente ligado a las comunidades andaluzas, pero no de manera exclusiva.

\section{Bibliografía}

\section{Documentos manuscritos}

Archivo General de Indias (AGI), Contratación, 251, N.1, R.10

\section{Libros y artículos}

Alcántara Castillo 2011 - J. A. Alcántara Castillo, Fallece el misionero don Carlos Guillena Rodríguez, hijo del pueblo de los Molares (Sevilla), "Cofrades" 23 de agosto de 2011, enlace web: http://cofrades.sevilla.abc.es/profiles/blogs/fallece-el-misionero-don-carlos-guillena-rodriguez-hijo-del

Barceló y Fuentes Benítez 2005 - E. Barceló y A. Fuentes Benítez, El Rocío en San Luis (Argentina). Consultar en: https://www.rocio.com/el-rocio-en-san-luis-argentina/.

Calderero de Aldecon 2018 - J. Calderero de Aldecoa, Una réplica exacta del Rocio en plena selva peruana para ayudar a niñas en exclusión, "Alfa y Omega. Semanario católico de información", 7 de septiembre de 2018. Consulta en: https://alfayomega.es/162475/una-replicaexacta-del-rocio-en-plena-selva-peruana-para-ayudar-a-ninas-en-exclusion

Carrasco Terriza 2002 - M. J. Carrasco Terriza, La iconografia de la Virgen del Rocio y su proceso de fijación, en: AA.VV. Ritos y ceremonias en el Mundo Hispano durante la Edad Moderna. Actas del II Encuentro Iberoamericano de Religiosidad y costumbres populares, Huelva, Servicio de Publicaciones de la Universidad, 2002, pp. 353-372.

Carrasco Terriza 1992 - M. J. Carrasco Terriza, Guía para visitar los Santuarios Marianos de Andalucía Occidental. Serie María en los pueblos de España, vol. 12, Madrid, Ediciones Encuentro, 1992. 
Cruz de Fuentes 1908 - L. Cruz de Fuentes, Documentos de las fundaciones religiosas y benéficas de la Villa de Almonte y apuntes para su historia, Huelva, Gálvez, 1908.

INFANTE GALÁN 1971 - J. Infante Galán, Rocio. La devoción mariana de Andalucía. Sevilla, Editorial Prensa Española, 1971.

Garrido Castellano 2017 - C. Garrido Castellano, Virgen del Rocio (Almonte-Huelva), en: R. López Guzmán y F. Montes González (coords.) Religiosidad andaluza en América. Repertorio iconográfico, Granada, Editorial de la Universidad, 2017, pp. 281-287.

Guerrero Granados 2019 - M. T. Guerrero Granados, 15 años en casa, "Boletín roceiro", n. 1 (1) 2019, p. 1.

Jiménez GARCía 2017 - M. A. Jiménez García, Y todo el mundo fue rociero, "ABC, Andalucia", 30 de mayo de 2017. Consulta en: https://sevilla. abc.es/andalucia/huelva/sevi-y-todo-mundo-rociero-201705301019 noticia.html

LÁzaro JóDAr 2010 - M. Lázaro Jódar, El Centro Andaluz Virgen del Rocío de Rosario celebra el Rocio, "España Exterior, el periódico de las comunidades españolas en el mundo”, 11 de junio de 2010, enlace web: https://www.espanaexterior.com/noticias/el-centro-andaluz-virgen-del-rocio-de-rosario-celebra-el-rocio-2/.

López Guzmán, Montes González 2017 - R. López Guzmán y F. Montes González (coords.) Religiosidad andaluza en América. Repertorio iconográfico, Granada, Editorial de la Universidad, 2017.

Romero-SÁnchez, Rui 2020 - G. Romero-Sánchez y A. J. Rui, Virgem do Rocio na América: fraternidade, cultura, fé e tradição, en: R. López Guzmán (coord.) Intercambios culturales, Andalucía - Brasil - Estados Unidos. En prensa.

Romero-SÁnchez 2019 - G. Romero-Sánchez, La Granada de las Indias. Análisis de las donaciones de Ultramar a través de sus protagonistas, en: G. Romero-Sánchez (ed.), Construyendo patrimonio. Mecenazgo y promoción artística entre América y Andalucía, Biblioteca Potestas, vol. 5. Castellón, Servicio de Publicaciones de la Universidad, 2019.

Vellés 2013 - L. Vellés, La Asociación Rociera de Pérez (Argentina) celebró su décimo Rocio, "España Exterior, el periódico de las comunidades españolas en el mundo", 11 de junio de 2013, enlace web: https:// www.espanaexterior.com/noticias/la-asociacion-rociera-de-perez-argentina-celebro-su-decimo-rocio-8/. 


\section{Recursos electrónicos}

Centro Cultural Andalucía de Buenos Aires (Argentina). Sitio web: http://www. cecaba.org.ar/modules.php?name=An_Rocio

Portal de Noticias: rocio.com/movil/noticias/ver.php?id=44\&site=514\&busqueda $=$

Página de Facebook de la Hermandad de la Virgen del Rocío de San Juan (Argentina) https://www.facebook.com/Hermandad-de-la-Virgen-del-Rocio-San-Juan-Argentina-1571678789808884/

Centro Espanhol do Paraná. Sitio web: https://www.centroespanhol.com.br/ eventos.

http://portalbelohorizonte.com.br/eventos/festa/gastronomia/24a-festa-espanhola-de-belo-horizonte-romeria-da-virgem-del-rocio

https://www.rocio.com/cgi-bin/yabb/YaBB.cgi?board=informacion;action=print;num=1279340935. Ver también: La Hermandad del Rocío de Brasil. Escrito por Periódico Rociero / Juan M. Curado. Portugal, domingo, 25 de abril de 2010.

Referencia: https://www.espanaexterior.com/noticias/dia-de-la-virgen-del-rocio -en-el-centro-cultural-andaluz-de-chile-8/

https://www.youtube.com/watch?v=a2Rc6WTryQ0\&feature=youtu.be.

Huelva, buenas noticias. Periódico, 22 mayo 2015. Consulta: 22/03/2019. Referencia digital: https://huelvabuenasnoticias.com/2015/05/22/el-rocio-usa-la-celebracion-de-la-romeria-almontena-en-california/

Referencia: http://www.elrocio.net/index.html.

http://www.elrocio.net/events.html

Página de Facebook de la Asociación Hermandad Andino Amazónica Nuestra Señora Virgen del Rocío. Referencia: https://www.facebook.com/ pages/category/Community-Service/Asociaci\%C3\%B3n-Hermandad-Andino-Amaz $\%$ C3\%B3nica-Ntra-Sra-Virgen-del-Roc\%C3\%ADo-Per\%C3\%BA-1174409032685676/

Página de Facebook del hogar de Nazaret. Referencia: https://www.facebook. com/HogarNazaretOficial/posts/2646297638791112

Referencia: https:/www.rocio.com/agrupacion-ntra-sra-del-rocio-de-meridavenezuela/\#/

Humilde, Fervorosa, Paciente y Caritativa Hermandad de Nuestra Señora del Rocío, Rocieros de Corazón. Sitio web: www.soyrociero.com 


\section{Summary}

The footprints of the road. Cult and devotion to our Lady of Rocío in American lands, immaterial culture of Andalusia

One of the most important Marian cults in Spain is that of El Rocío, in whose hermitage thousands of faithful congregate every year from many different places. Its devotional roots in other countries are fundamentally linked to groups of Andalusian immigrants, although this is not the only way of penetrating them. In their celebration, they generally reproduce on a small scale and overcoming geographical distances, the basic elements of the Almonte pilgrimage, deepening in cultural and social aspects, beyond the religious ones, which sink their roots in the rich Andalusian immaterial heritage. In this article we will analyze the traces of their devotion in countries such as Argentina, the United States, Colombia, Brazil, Mexico and Peru, among others.

Keywords: Our Lady of Rocío, intangible heritage, Andalusia, faith, devotional paths

\section{Streszczenie}

Ślady drogi. Kult i nabożeństwo do Matki Bożej z Rocío na ziemiach amerykańskich jako niematerialne dziedzictwo Andaluzji

Jednym z najważniejszych kultów maryjnych w Hiszpanii jest kult Matki Bożej z El Rocío, w której pustelni co roku gromadzą się tysiące wiernych napływających $\mathrm{z}$ różnych miejsc. Przejawy tego kultu w innych krajach świata są zasadniczo związane z grupami andaluzyjskich imigrantów, choć nie była to jedyna droga jego rozprzestrzeniania się. Obchody święta Matki Bożej z Rocío poza granicami Hiszpanii polegają generalnie na odtwarzaniu na mniejszą skalę podstawowych elementów pielgrzymki do Almonte przy jednoczesnym zagłębianiu się nie tylko w jej aspekty religijne, lecz także w kulturowe i społeczne, mające swoje korzenie w bogatym niematerialnym dziedzictwie Andaluzji. W tym artykule przeanalizujemy ślady tego kultu w takich krajach, jak między innymi: Argentyna, Stany Zjednoczone, Kolumbia, Brazylia, Meksyk czy Peru.

Słowa kluczowe: Matka Boża z Rocío, dziedzictwo niematerialne, Andaluzja, wiara, szlaki pielgrzymkowe 